\title{
Coupling of Energy Metabolism and Synaptic Transmission at the Transcriptional Level: Role of Nuclear Respiratory Factor 1 in Regulating both Cytochrome $c$ Oxidase and NMDA Glutamate Receptor Subunit Genes
}

\author{
Shilpa S. Dhar and Margaret T. T. Wong-Riley \\ Department of Cell Biology, Neurobiology, and Anatomy, Medical College of Wisconsin, Milwaukee, Wisconsin 53226
}

\begin{abstract}
Neuronal activity and energy metabolism are tightly coupled processes. Regions high in neuronal activity, especially of the glutamatergic type, have high levels of cytochrome $c$ oxidase (COX). Perturbations in neuronal activity affect the expressions of COX and glutamatergic NMDA receptor subunit 1 (NR1). The present study sought to test our hypothesis that the coupling extends to the transcriptional level, whereby NR1 and possibly other NR subunits and COX are coregulated by the same transcription factor, nuclear respiratory factor 1 (NRF-1), which regulates all COX subunit genes. By means of multiple approaches, including in silico analysis, electrophoretic mobility shift and supershift assays, in vivo chromatin immunoprecipitation, promoter mutations, and real-time quantitative PCR, NRF-1 was found to functionally bind to the promoters of Grin 1 (NR1), Grin $2 b$ (NR2b) and COX subunit genes, but not of Grin2a and Grin $3 a$ genes. These transcripts were upregulated by $\mathrm{KCl}$ and downregulated by tetrodotoxin (TTX) in cultured primary neurons. However, silencing of NRF-1 with small interference RNA blocked the upregulation of Grin1, Grin2b, and COX induced by KCl, and overexpression of NRF-1 rescued these transcripts that were suppressed by TTX. NRF-1 binding sites on Grin1 and Grin2b genes are also highly conserved among mice, rats, and humans. Thus, NRF-1 is an essential transcription factor critical in the coregulation of NR1, NR2 $b$, and COX, and coupling exists at the transcriptional level to ensure coordinated expressions of proteins important for synaptic transmission and energy metabolism.
\end{abstract}

Key words: depolarization; NMDA receptor; NRF-1; overexpression; siRNA silencing; TTX

\section{Introduction}

NMDA receptor (NR) is a major glutamate receptor type that has a unique ligand-gated calcium channel with voltage-dependent magnesium block, and it plays an important role in neuronal plasticity, learning, and memory by mediating most of the excitatory synaptic transmission in the CNS (Choi, 1988; Meguro et al., 1992; Mori and Mishina, 1995). NR function is dictated by its subunit composition (Monyer et al., 1994), made up of an essential NR1 subunit in combination with NR2 (A-D) and/or NR3 (A-B) subunits in a heterotetramer that provides functional molecular diversity (Dingledine et al., 1999). NMDA receptormediated synaptic transmission is an integral part of neuronal activity, which is tightly coupled to energy metabolism (WongRiley, 1989). Neuronal activity that involves more excitatory depolarizing transmission has a greater energy demand, as membrane repolarization after depolarization requires ATP-

Received Aug. 5, 2008; revised 0ct. 15, 2008; accepted Nov. 14, 2008.

This work was supported by National Institutes of Health Grant EY018441. It gives us great pleasure to thank Dr. Richard Scarpulla for his generous gift of NRF-1 antibodies and pSG5NRF-1 plasmid, and Dr. P. Aebischer for his gift of PLVTHM. We thank Drs. H. Liang and H. Meng for assisting in the construction of shRNA vectors.

Correspondence should be addressed to Margaret T. T. Wong-Riley, Department of Cell Biology, Neurobiology, and Anatomy, Medical College of Wisconsin, Milwaukee, WI 53226. E-mail: mwr@mcw.edu.

DOI:10.1523/JNEUROSCI.3704-08.2009

Copyright $\odot 2009$ Society for Neuroscience $\quad$ 0270-6474/09/290483-10\$15.00/0 dependent $\mathrm{Na}^{+} / \mathrm{K}^{+}$-ATPase to actively pump cations against their concentration and electrical gradients. Most of the ATP in neurons is derived from oxidative metabolism, and cytochrome $c$ oxidase (COX) is a critical energy-generating enzyme (WongRiley, 1989). It is an integral protein of the inner mitochondrial membrane, catalyzing the final step of oxidative metabolism (Wikström et al., 1981). Regions rich in COX have higher levels of glutamatergic and NMDA receptor-mediated synapses, and when excitatory transmission is suppressed, such as with tetrodotoxin (TTX)-induced impulse blockade, the level of COX as well as of NMDA receptor subunit 1 are reduced (Wong-Riley et al., 1998a,b). Changes in the level of neuronal activity thus induce a concomitant change in both COX and NMDA receptors. Is it possible that the same molecular mechanism regulates the transcriptional expression of both COX and glutamate receptors? The goal of the present study is to test for the existence of a common transcription factor that can play such a dual role. Nuclear respiratory factor 1 (NRF-1) is a transcription factor recently found to functionally regulate all 13 subunits of COX (Dhar et al., 2008). Its role in the regulation of NMDA subunit genes is entirely unknown. The goal of the present study is to use multiple approaches to test our hypothesis that NRF-1 dually regulates the expressions of both COX and NMDA receptor subunits in neurons. 
Table 1. EMSA probes

\begin{tabular}{|c|c|c|}
\hline Gene promoter & Position $^{a}$ & Sequence \\
\hline \multirow[t]{2}{*}{ Grin1 } & $-90 /-55$ & F 5' TTTTGCGCGCTCCAAGCATTTACGCCAACGCAGGCGCGC 3' \\
\hline & & R3'CGCGCGAGGTTCGTAAATGCGGTTGCGTCCGCGCGTTT 5' \\
\hline \multirow[t]{2}{*}{ Grin2a } & $-263 /-233$ & F5' $5^{\prime} T T T G C T G G C G C G G G A C G C C G A G C C T G G G A G G G C 3^{\prime}$ \\
\hline & & R 3' CGACCGCGCCCTGCGGCTCGGACCCTCCCGTTTT 5' \\
\hline \multirow[t]{2}{*}{ Grin2b } & $-74 /-49$ & F 5' TTTTGGTGTGCGCGCGCGAGCGCACACTGC 3' \\
\hline & & R 3'CCACACGCGCGCGCTCGCGTGTGACGTTTT 5' \\
\hline \multirow[t]{2}{*}{ Grin3a } & $-98 /-73$ & F5' TTTTGCTCTTCCCACACACGCCCCCAGGT 3' \\
\hline & & R 3'CGAGAAGGGTGTGTGCGGGGGTCCATTTT 5' \\
\hline \multirow{6}{*}{$\begin{array}{l}\text { Grin1 } \\
\text { NRF-1 mutant } \\
\text { Grin2b } \\
\text { NRF-1 mutant } \\
\text { Rat Cyt C }\end{array}$} & $-90 /-55$ & F 5' TTTTGCGCGCTCCAATTTTTTACGCCAACTTTGGCGCGC 3' \\
\hline & & R 3'CGCGCGAGGTTAAAAAATGCGGTTGAAACCGCGCGTTTT 5' \\
\hline & $-74 /-49$ & F5' TTTTGGTGITTTCGCGITTGGGCACACTGC $3^{\prime}$ \\
\hline & & R 3'CCACAAAAGCGCAAACGCGTGTGACGTTTT 5' \\
\hline & $-172 /-147$ & F 5' TTTTCTGCTAGCCCGCATGCGCGCGCACCTTA3' \\
\hline & & R 3' GACGATCGGGCGTACGCGCGCGTGGAATTTTT5' \\
\hline
\end{tabular}

Putative NRF-1-binding sites are in boldface. Mutated nucleotide sequences are underlined. F, Forward; R, reverse; Cyt C, cytochrome $C$.

${ }^{a}$ Positions of probes are given relative to TSP.

\section{Materials and Methods}

All experiments were performed in accordance with the U.S. National Institutes of Health Guide for the Care and Use of Laboratory Animals and the Medical College of Wisconsin regulations. All efforts were made to minimize the number of animals and their suffering.

Cell culture. Murine neuroblastoma N2a cells were obtained from the American Type Culture Collection (ATCC, CCL-131). Cells were grown in DMEM supplemented with $10 \%$ fetal bovine serum, 50 units $/ \mathrm{ml} \mathrm{pen-}$ icillin, and $100 \mu \mathrm{g} / \mathrm{ml}$ streptomycin (Invitrogen) at $37^{\circ} \mathrm{C}$ in a humidified atmosphere with $5 \% \mathrm{CO}_{2}$.

Rat primary cortical neurons were cultured as described previously (Ongwijitwat and Wong-Riley, 2005). Briefly, 1-d-old neonatal rat pups were killed by decapitation. Brains were removed from the skull and the meninges were removed. Visual cortical tissue was dissected, trypsinized, and triturated to release individual neurons. These primary cortical neurons were then plated in $35 \mathrm{~mm}$ poly-L-lysine-coated dishes at a density of 50,000 cells/dish. Cells were maintained in Neurobasal-A media supplemented with B27 (Invitrogen). Ara-C (Sigma) was added to the media to suppress the proliferation of glial cells.

In silico analysis of murine NMDA receptor subunit promoters. DNA sequences surrounding the transcription start points (TSPs) of NMDA receptor subunit genes (Grin1, Grin2a-2d, and Grin3a-b for NR1, 2a-2d and $3 a-b$, respectively) were derived from the mouse genome database in GenBank, using Genomatix Gene2promoter software. These promoter sequences encompassed $1 \mathrm{~kb}$ upstream and up to $200 \mathrm{bps}$ downstream (excluding protein-coding sequence) of the TSP of each gene analyzed. Computer-assisted search for putative NRF-1 core binding sequences "GCGCAT/CGC" or "GCGCAG/CGC" was conducted on each promoter sequence. Alignment of human, mouse, and rat promoter sequences was done as previously described, using the Genome VISTA genome alignment tool (Ongwijitwat and Wong-Riley, 2005). Murine Grin1 and Grin $2 b$ promoter sequences were compared with rat and human genomic sequences using a 5-bp calculation window. Regions of high homology and/or that contain known NRF-1 binding sites were compared for the conservation of NRF-1 binding.

Electrophoretic mobility shift and supershift assays. Electrophoretic mobility shift assays (EMSAs) to assay NRF-1 interactions with putative binding elements on all NMDA receptor subunit promoters were performed with methods as previously described (Dhar et al., 2008). Briefly, oligonucleotide probes with putative NRF-1 binding site on each promoter (Table 1, Grin 1, 2a, 2b, and $3 a$ subunits) based on in silico analysis were synthesized, annealed, and labeled by a Klenow fragment fill-in reaction with $\left[{ }^{32} \mathrm{P}\right]$ dATP $(50 \mu \mathrm{Ci} / 200 \mathrm{ng})$. Each labeled probe was incubated with $2 \mathrm{~g}$ of calf thymus DNA and $5 \mathrm{~g}$ of HeLa nuclear extract (Promega) and processed for EMSA. Supershift assays were also performed and, in each reaction, 1-1.5 $\mu \mathrm{g}$ of NRF-1-specific antibodies (polyclonal goat antibodies, gift from Dr. Richard Scarpulla, Northwest-
Table 2. ChIP assay primers

\begin{tabular}{|c|c|c|c|}
\hline Gene promoter & Position $^{a}$ & Sequence & Amplicon length \\
\hline Grin1 & -149 to +87 & $\begin{array}{l}\text { F5' TGTCCCTGGTTCTCTGTATGC } 3^{\prime} \\
\text { R5'AAAGACAGCTGCCTGGACTG 3' }\end{array}$ & $236 \mathrm{bps}$ \\
\hline Grin2a & -282 to +10 & $\begin{array}{l}\text { F5' GAGAGAGGCTGCGGTGAGT 3' } \\
\text { R55'CCGGCTACTGGGAGTTGTG 3' }\end{array}$ & 291 bps \\
\hline Grin2b & -83 to +193 & $\begin{array}{l}\text { F5'GAGTGAGGGGGTGATGGAG 3' } \\
\text { R5'AATCTCAGGGTGTGGAGAGC } 3^{\prime}\end{array}$ & $276 \mathrm{bps}$ \\
\hline Grin3a & -228 to +17 & $\begin{array}{l}\text { F5'CTGGTACTCTGAGGCCCTTG 3' } \\
\text { R5'AAAGGTTGACAGGAGCCAGA 3' }\end{array}$ & $245 \mathrm{bps}$ \\
\hline TFB2M promoter & -64 to +115 & $\begin{array}{l}\text { F5'GAAGCGAGTGAGCAAAGGAC } 3^{\prime} \\
\text { R55'GGTCCCCTCATCCTCCTCTA 3' }\end{array}$ & 179 bps \\
\hline$\beta$-actin exon 5 & -134 to +53 & $\begin{array}{l}\text { F5'GCTCTTTTCCAGCCTTCCTT 3' } \\
\text { R5' }\end{array}$ & 187 bps \\
\hline
\end{tabular}

F, Forward; $R$, reverse.

${ }^{a}$ Positions of amplicons are given relative to TSP.

Table 3. PCR cloning primers

\begin{tabular}{|c|c|}
\hline & Primer sequence \\
\hline \multicolumn{2}{|l|}{ Cloning primers } \\
\hline \multirow[t]{2}{*}{ Grin1 } & F 5'AAGGTACCCGGCCGTCACACCTATTCT 3' \\
\hline & R 5'AAAAGCTTGAAAAGGCGAAAAAGACAGC 3' \\
\hline \multirow[t]{2}{*}{ Grin2b } & F 5'AAAGATCTCACACACACACACACACACACA \\
\hline & R 5'AAAAGCTTGGAGGAGGGGGAGAGTAAGA \\
\hline \multirow[t]{2}{*}{ MC0Х6а1 } & F 5'AAGGTACCGCGTCTTCCTCGCAGATACT 3' \\
\hline & R 5'AAAAGCTTGGAACTACACCGGCGCGC 3' \\
\hline \multicolumn{2}{|c|}{ Mutagenesis primers } \\
\hline \multirow[t]{2}{*}{ Grin1Mut } & F 5' CAAGCATTTACGCCAACTTTGGCTTTTGTCAGGAGGCGCGCGCT 3' \\
\hline & R 5'AGCGCGCGCCTCCTGACAAAAGCCAAAGTTGGCGTAAATGCTTG 3' \\
\hline \multirow[t]{2}{*}{ Grin2bMut } & F 5' GTGTGTGTGGTGTGCTTTCGCGATTGCACACTGCTGTACA 3’ \\
\hline & R5' TGTACAGCAGTGTGCAATCGCGAAAGCACACCACACACAC $3^{\prime}$ \\
\hline \multirow[t]{2}{*}{ MC0X6a1Mut } & F 5'CACAGGAACGGGGCTTTTGCGCGCTCTCGCTC 3' \\
\hline & R 5'GAGCGAGAGCGCGCAAAAGCCCCGTTCCTGTG 3' \\
\hline
\end{tabular}

Putative NRF-1-binding sites are in boldface. Mutated nucleotide sequences are underlined. F, Forward; R, reverse.

ern University, Chicago, IL) were added to the probe/nuclear extract mixture and incubated for $20 \mathrm{~min}$ at room temperature. For competition, 100-fold excess of unlabeled oligonucleotides were incubated with nuclear extract before adding labeled or nonspecific oligonucleotides. Shift reactions were loaded onto $4 \%$ polyacrylamide gel and run at $200 \mathrm{~V}$ for $2.5 \mathrm{~h}$ in $0.25 \times \mathrm{TBE}$ buffer. Results were visualized by autoradiography. Rat cytochrome $c$ with NRF-1 binding site at position $-172 /-147$ was designed as previously described (Evans and Scarpulla, 1990) and used as a positive control. NRF-1 mutants with mutated sequences as shown in Table 1 were used as negative controls.

Chromatin immunoprecipitation assays. Chromatin immunoprecipitation (ChIP) assays were performed similar to those previously described (Dhar et al., 2008). Briefly, 750,000 N2a cells were used for each immunoprecipitation and were fixed with $1 \%$ formaldehyde for $10 \mathrm{~min}$ at room temperature. ChIP assay kit (Upstate) was used with minor modifications. Following formaldehyde fixation, cells were resuspended in a swelling buffer ( $5 \mathrm{~mm}$ PIPES, pH 8.0, $85 \mathrm{~mm} \mathrm{KCl}$, and 1\% Nonidet $\mathrm{P}-40$, and protease inhibitors added right before use) and homogenized 10 times in small pestle Dounce tissue homogenizer $(7 \mathrm{ml})$. Nuclei were then isolated by centrifugation before being subjected to sonication. The sonicated lysate was immunoprecipitated with either $0.2 \mu \mathrm{g}$ of NRF-1 polyclonal rabbit antibodies (a gift from Dr. Scarpulla) or $2 \mu \mathrm{g}$ of antinerve growth factor receptor (NGFR) p75 polyclonal goat antibodies (C20 from Santa Cruz Biotechnology). Semiquantitative PCR was performed using $1 / 20$ th of precipitated chromatin. Primers targeting promoter sequences near TSP of NMDA receptor subunit genes were designed (Table 2) using approaches as previously described (Ongwijitwat and Wong-Riley, 2005). Transcription factor B2 of mitochondria (TFB2M) promoter, previously found to be activated by NRF-1 in neurons (Dhar et al., 2008), was used as a positive control, and exon 5 of $\beta$-actin gene was used as a negative control (Table 2). PCRs were per- 
Table 4. Primers for real-time PCP

\begin{tabular}{|c|c|c|c|}
\hline Gene & Sequence & Amplicon length & $T_{\mathrm{m}}$ \\
\hline \multirow[t]{2}{*}{ Grin1 } & F 5'TGGCTTCTGCATAGACCTGCTCAT 3' & \multirow[t]{2}{*}{$117 \mathrm{bps}$} & \multirow[t]{2}{*}{$60^{\circ}$} \\
\hline & R 5'TTGTTGCTGTTGTTTACCCGCTCC $3^{\prime}$ & & \\
\hline \multirow[t]{2}{*}{ Grin2a } & F 5'TCTATGACGCAGCCGTCTTGAACT 3' & \multirow[t]{2}{*}{92 bps } & \multirow[t]{2}{*}{$60^{\circ}$} \\
\hline & R 5'TGTGGTAGCAAAGATGTACCCGCT 3' & & \\
\hline \multirow[t]{2}{*}{ Grin2b } & F 5'TCATGGTATCTCGCAGCAATGGGA 3' & \multirow[t]{2}{*}{108 bps } & \multirow[t]{2}{*}{$60^{\circ}$} \\
\hline & R 5'ACCGCAGAAACAATGAGCAGCATC 3' & & \\
\hline \multirow[t]{2}{*}{ Grin3a } & F 5'AGTGACCCTTTCTCCTTCCTGCAA 3' & \multirow[t]{2}{*}{130 bps } & \multirow[t]{2}{*}{$60^{\circ}$} \\
\hline & R 5'TGTGCAGGACTAAGCTGACCAAGT 3' & & \\
\hline \multirow[t]{2}{*}{ NRF-1 } & F 5'GGCACAGGCTGAGCTGATG 3' & \multirow[t]{2}{*}{90 bps } & \multirow[t]{2}{*}{$59.5^{\circ}$} \\
\hline & R 5'CTAGTTCCAGGTCAGCCACCTTT 3' & & \\
\hline \multirow[t]{2}{*}{ NRF- $2 \alpha$} & F 5' CTCCCGCTACACCGACTAC 3' & \multirow[t]{2}{*}{145 bps } & \multirow[t]{2}{*}{$59.5^{\circ}$} \\
\hline & R 5'TCTGACCATTGTTTCCTGTTCTG 3' & & \\
\hline \multirow[t]{2}{*}{$\mathrm{COX} 2$} & F 5'TGGCTTACAAGACGCTACATC 3' & \multirow[t]{2}{*}{201 bps } & \multirow[t]{2}{*}{$59.5^{\circ}$} \\
\hline & R 5'GGAGGGAAGGGCAATTAGAA 3' & & \\
\hline \multirow[t]{2}{*}{$\mathrm{CON6c}$} & F 5'AGCGTCTGCGGGTTCATA 3' & \multirow[t]{2}{*}{154 bps } & \multirow[t]{2}{*}{$60^{\circ}$} \\
\hline & R 5'GCCTGCCTCATCTCTTCAAA 3' & & \\
\hline \multirow[t]{2}{*}{$\beta$-actin } & F 5'GGCTGTATTCCCTCCATCG 3' & \multirow[t]{2}{*}{154 bps } & \multirow[t]{2}{*}{$59.5^{\circ}$} \\
\hline & R 5'CCAGTTGGTAACAATGCCATGT 3' & & \\
\hline \multirow[t]{2}{*}{$18 \mathrm{~S}$} & F 5' CGCGGTTCTATTTTGTTGGT 3' & \multirow[t]{2}{*}{219 bps } & \multirow[t]{2}{*}{$59.5^{\circ}$} \\
\hline & R 5'AGTCGGCATCGTTTATGGTC 3' & & \\
\hline
\end{tabular}

$F$, Forward; $R$, reverse

formed with the EX Taq hot-start polymerase (Takara Mirus Bio) with the following cycling parameters: $30 \mathrm{~s}$ denaturation at $94^{\circ} \mathrm{C}, 30 \mathrm{~s}$ annealing at $59.5^{\circ} \mathrm{C}$, and $20 \mathrm{~s}$ extension at $72^{\circ} \mathrm{C}(32-36$ cycles per reaction $)$. All reactions were hot-started by heating to $94^{\circ} \mathrm{C}$ for $120 \mathrm{~s}$. Use of hot-start polymerase and PCR additives significantly improved the quality and reproducibility of ChIP. PCR products were visualized on $2 \%$ agarose gels stained with ethidium bromide.

Construction and transfection of luciferase reporter vectors for promoter mutagenesis study. Luciferase reporter constructs of NR1 promoters were made by PCR cloning the proximal promoter sequences using genomic DNA prepared from mouse N2a cells as template, digesting with KpnI and HindIII, and ligating the product directionally into $p$ GL3 basic (Promega). Sequences of primers used for PCR cloning and mutagenesis primers are provided in Table 3. Subunit COX6a1 clone was used from our previous study (Dhar et al., 2008). Site-directed mutations of putative NRF-1 binding site on each promoter were generated using QuikChange site-directed mutagenesis kit (Stratagene). All constructs were verified by sequencing.

Each promoter construct was transfected into N2a cells in a 24-well plate using Lipofectamine 2000. Each well received $0.6 \mu \mathrm{g}$ of reporter construct and $0.03 \mu \mathrm{g}$ of pCMV $\beta$ gal, which constitutively expressed $\beta$-galactosidase. Transfected neurons were stimulated with $\mathrm{KCl}$ at a final concentration of $20 \mathrm{~mm}$ in the culture media for $5 \mathrm{~h}$ as previously described (Yang et al., 2006). After $5 \mathrm{~h}$ of treatment, cell lysates were harvested and measured for luciferase activity as described previously (Dhar et al., 2008). Data from six independent transfections were averaged for each promoter construct.

Plasmid construction of NRF-1 shRNA. The pLL3.7 vector with U6 promoter and puromycin resistance (Addgene) was used to express murine NRF-1 small hairpin RNA (shRNA) (GenBank accession no. for NRF-1: NM_010938). Four shRNA sequences were selected and constructed with a common, noncoding, hairpin loop region (TTCAAGAGA): 5'-GAAAGCTGCAAGCCTATCT-3'; 5' -GCCACAGGAGGTTAATTCA-3'; 5' -GCATTACGGACCATAGTTA-3'; and 5' -AGAGCATGATCCTGGAAGA-3'.

Empty vectors and scrambled shRNA served as negative controls. A green fluorescent protein-containing reporter vector PLVTHM (a gift from Dr. P. Aebischer, Swiss Federal Institute of Technology, Zurich, Switzerland) was used to identify transfected N2a cells and primary neurons. The basic gene cloning method was followed and as described previously (Ongwijitwat and Wong-Riley, 2006). To determine the effect of silencing NRF-1 expression on endogenous targets, N2a cells or primary neurons were plated in $35 \mathrm{~mm}$ dishes at a density of 5-8 $\times 10^{6}$ cells/dish. Cells were cotransfected $3 \mathrm{~d}$ postplating with either $4 \mu \mathrm{g}$ of the
shRNA plasmids (four sequences at equal amounts) or $4 \mu \mathrm{g}$ of the empty vector and $1.5 \mu \mathrm{g}$ of $p L L 3.7$ vector (for primary neurons, $0.25 \mu \mathrm{g}$ of the shRNA plasmids and $1 \mu \mathrm{g}$ of $p L L 3.7$ vector), using Lipofectamine 2000 as described previously (Ongwijitwat and Wong-Riley, 2006; Dhar et al., 2008). Puromycin at a final concentration of $0.5 \mu \mathrm{g} / \mathrm{ml}$ was added to the culture medium on the second day after transfection to select for purely transfected cells. Green fluorescence was observed to monitor transfection efficiency. Transfection efficiency for N2a cells ranged from 40 to $75 \%$, while that for primary cortical neurons was from 40 to $60 \%$. However, puromycin selection effectively yielded $100 \%$ of transfected cells. N2a cells transfected with shRNA against NRF-1 were further stimulated with $\mathrm{KCl}$ at a final concentration of $20 \mathrm{~mm}$ in the culture media for $5 \mathrm{~h}$ as previously described (Yang et al., 2006). After $5 \mathrm{~h}$ of treatment, cells were harvested for RNA isolation.

RNA isolation and cDNA synthesis. Total RNA was isolated by RNeasy kits (Qiagen) according to the manufacturer's instructions. Three micrograms of total RNA was treated with DNase I and purified by phenolchloroform. cDNA was synthesized using random hexamer primers and SuperScript II RNase H-Reverse Transcriptase (Invitrogen) according to the manufacturer's instructions.

Real-time quantitative PCR. Real-time quantitative PCRs were performed in a Cepheid Smart Cycler Detection system (Cepheid). SyBr Green (BioWhittaker Molecular Application) and EX Taq real-time quantitative PCR hot-start polymerase were used following the manufacturer's protocols and as described previously (Dhar et al., 2008). Primer sequences are shown in Table 4. PCR runs: hot start $2 \mathrm{~min}$ at $95^{\circ} \mathrm{C}$, denaturation $10 \mathrm{~s}$ at $95^{\circ} \mathrm{C}$, annealing $15 \mathrm{~s}$ according to the $T \mathrm{~m}$ of each primer, and extension $10 \mathrm{~s}$ at $72^{\circ} \mathrm{C}$ for $15-30$ cycles. Melt curve analyses verified the formation of single desired PCR product. Mouse $\beta$-actin for N2a cells and rat $18 \mathrm{~s}$ for primary neurons were used as internal controls, and the $\Delta \Delta C_{\mathrm{T}}$ method (Livak and Schmittgen, 2001) was performed for the relative amount of transcripts.

Western blot assays. Control and NRF-1 shRNA samples were loaded onto $10 \%$ SDS-PAGE gel and electrophoretically transferred onto polyvinylidene difluoride membranes (Bio-Rad). Subsequent to blocking, blots were incubated in primary antibodies [polyclonal antibodies against NRF-1 (1:500; a gift from Dr. Scarpulla,), NR1 (1:200), NR2A (1:200), NR2B (1:200) (all from Millipore)], or NR3A (1:200; P20 from Santa Cruz Biotechnology). Monoclonal antibodies against $\beta$-actin (Sigma) at 1:3000 dilution were used as loading controls. Blots were then incubated in secondary antibodies (goat-anti-rabbit, goat-anti-mouse, or rabbit-anti-goat; Millipore), reacted with ECL, and exposed to autoradiographic film (Santa Cruz Biotechnology). Quantitative analyses of relative changes were done with an Alpha Imager (Alpha Innotech).

NRF-1 overexpression and TTX treatment. $p S G 5 N R F-1$ plasmid (a gift from Dr. Scarpulla) was used for NRF-1 overexpression. N2a cells and primary neurons were each plated in $35 \mathrm{~mm}$ dishes at a density of $2-5 \times$ $10^{5}$ cells/dish. N2a cells were cotransfected $3 \mathrm{~d}$ postplating with either 2.5 $\mu \mathrm{g}$ of the $p S G 5 N R F-1$ plasmid or an empty vector plus $0.5 \mu \mathrm{g}$ of $p L L 3.7$ vector, using Lipofectamine 2000 (Invitrogen) at a 1:3 ratio. Procedures were identical for the transfection of primary neurons, except that $2 \mu \mathrm{g}$ pSG5NRF-1 plasmid were used. Puromycin at a final concentration of 0.5 $\mu \mathrm{g} / \mathrm{ml}$ was added on the second day after transfection to select for purely transfected cells. After $1 \mathrm{~d}$ of overexpression, TTX at a final concentration of $0.4 \mu \mathrm{M}$ was added to the culture media for $3 \mathrm{~d}$. N2a cells and primary neurons were harvested on the fourth day for RNA isolation.

Statistical analysis. Significance among group means was determined by ANOVA. Significance between two groups was analyzed by Student's $t$ test. $p$ values of 0.05 or less were considered significant.

\section{Results}

\section{In silico promoter analysis of NMDA receptor subunit genes}

Proximal promoters of murine NR subunit genes with DNA sequence $1 \mathrm{~kb} 5^{\prime}$ upstream and 100 bps beyond $3^{\prime}$ of TSPs were analyzed in silico for potential NRF-1 binding sites (Table 1). Grin1 (NR1) and Grin2b (NR2b) promoters showed atypical sequence for NRF-1 binding but had the invariant GCA core described previously for COX subunit genes (Dhar et al., 2008), 
whereas Grin2a (NR2a) had atypical NRF-1 site lacking the GCA core. Other NMDA receptor subunits Grin2c (NR2c), Grin2d (NR2d) and Grin3b (NR3b) also had atypical NRF-1 binding sites without the GCA core. NR3a lacked both typical and atypical NRF-1 binding sites, and was used as a negative control in subsequent studies.

\section{In vitro binding of NMDA receptor} subunits with NRF-1

In vitro EMSAs were performed using ${ }^{32} \mathrm{P}$ labeled probes (Table 1 ) to determine the specificity of NRF-1 binding to promoters of murine NR subunits (Grin1, 2a, and $2 b$ ), with Grin $3 a$ as the negative control (Fig. 1). Rat cytochrome $c$ promoter with NRF-1 site on positions -172 / - 147 served as a positive control (Dhar et al., 2008), and it formed specific DNA/NRF-1 shift and supershift complexes (Fig. $1 A$, lanes 1 and 5, respectively). When an excess of unlabeled probe was added as a competitor, no shift band was formed (Fig. $1 A$, lane 4). However, an excess of unlabeled mutant NRF-1 probes did not prevent the formation of a shift complex (Fig. $1 A$, lane 3 ). To rule out any nonspecific antibody-oligonucleotide interactions, labeled oligonucleotides were incubated with NRF-1 antibody without HeLa nuclear extract, and no shift bands were observed (Fig. $1 A$, lane 2; Fig. $1 B$, lanes 1 and $6)$. As shown in Figure $1 B$, Grin1 and Grin $2 b$ promoters formed specific DNAprotein shift complexes when incubated with purified HeLa nuclear extract (Fig. $1 \mathrm{~B}$, lanes 2 and 7, respectively). Competition with excess unlabeled probes eliminated these complexes (Fig. $1 B$, lanes 3 and 8 ), whereas the addition of mutant NRF-1 probes had no effect (Fig. $1 B$, lanes 4 and 9). A supershift band was produced when anti-NRF-1 antibodies were added to shift assays of Grin 1 and Grin2b, respectively (Fig. $1 B$, lanes 5 and 10 , respectively). Grin 1 and Grin $2 b$ mutant NRF-1 probes yielded no band or complexes (Fig. $1 B$, lanes 13 and 14). Grin $2 a$ and Grin3a lacked NRF-1 binding sites and did not produce any shift bands (Fig. $1 B$, lanes 11 and 12), verifying that the presence of the GCA core is essential for NRF-1 binding.

\section{In vivo NRF-1 interactions with NMDA receptor} subunit promoters

ChIP assays were performed to verify NRF-1 interactions with NMDA receptor subunits in vivo. $\beta$-Actin exon 5 served as a negative control, whereas transcription factor B2 of mitochondria (TFB2M) with a known NRF-1 binding site (Gleyzer et al., 2005; Dhar et al., 2008) served as a positive control. Parallel immunoprecipitation assays were performed with the same N2a cell
B

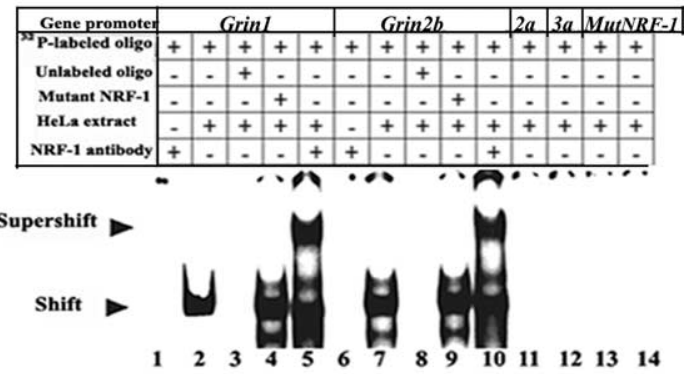

$\beta$-Actin Exon 5
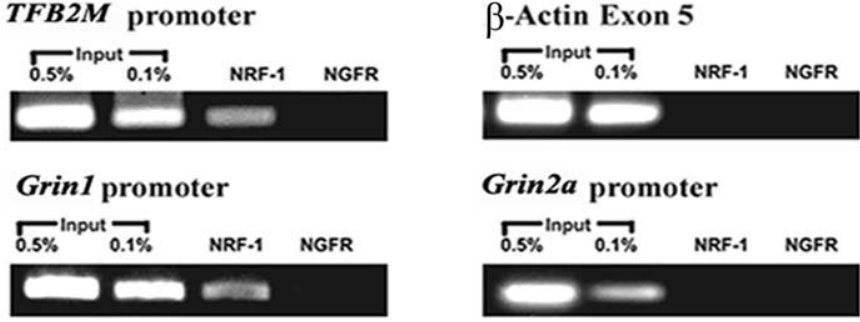

Grin2a promoter

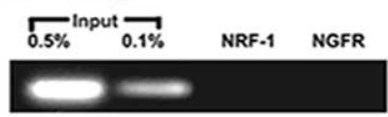

Grin $2 b$ promoter

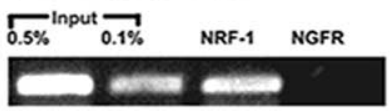

\section{Grin3a promoter}

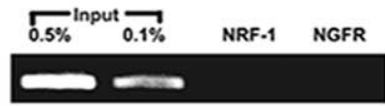

Relative luciferase assay

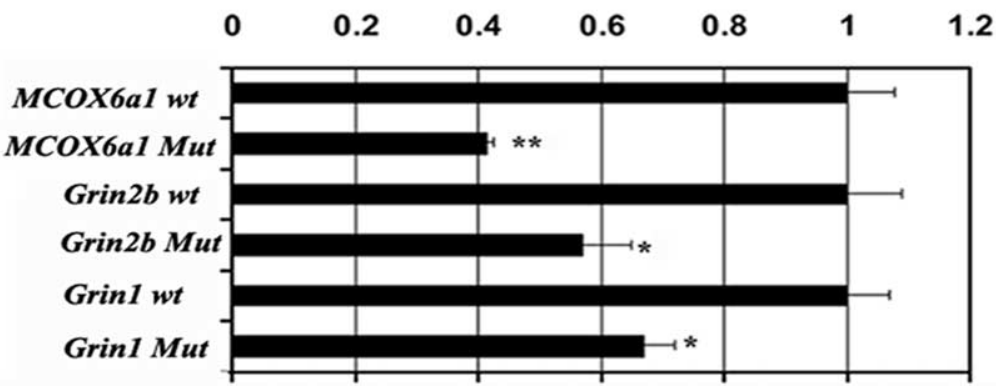

Figure 1. In vitro and in vivo interactions between NRF-1 and NMDA receptor subunit genes and promoter mutational analyses. $A, B$, EMSAs for NRF-1. ${ }^{32}$ P-labeled oligonucleotides (specific to each promoter tested), excess unlabeled oligos (specific to each promoter) as competitors, excess unlabeled mutant NRF-1 (mutating NRF-1 site for each promoter) as competitors, HeLa extract, and NRF-1 antibodies are indicated by a plus ( + ) or a minus ( - ) sign. Arrowheads indicate NRF-1 shift and supershift complexes. The positive control, cytochrome $c(C y t)$, shows shift $(A$, lane 1$)$ and supershift $(A$, lane 5$)$ bands, while excess unlabeled competitors did not yield any band ( $\boldsymbol{A}$, lane 4). Grin1 and Grin2b subunits have specific shift ( $\boldsymbol{B}$, lanes 2 and 7 ) and supershift ( $\boldsymbol{B}$, lanes 5 and 10) bands that are eliminated by excess unlabeled competitors ( $\boldsymbol{B}$, lanes 3 and 8 ), while Grin2a and Grin3a had no bands ( $\boldsymbol{B}$, lanes 11 and 12). Labeled mutated NRF-1 site on Grin 1 and Grin2b were negative controls ( $\boldsymbol{B}$, lanes 13 and 14 respectively). Excess unlabeled and mutated NRF-1 sites could not compete $(\boldsymbol{A}$, lane $3 ; \boldsymbol{B}$, lanes 4,9$)$. Labeled oligos with NRF-1 antibodies alone did not yield any band $(\boldsymbol{A}$, lane $2 ; \boldsymbol{B}$, lanes 1,6$) . \boldsymbol{C}$, ChIP assays. Input lanes represent $0.5 \%$ and $0.1 \%$ of chromatin. TFB2M promoter was the positive control and $\beta$-actin was the negative control. Grin 1 and Grin $2 b$ promoters coimmunoprecipitated with NRF-1, while Grin2a and Grin3a did not. Anti-nerve growth factor receptor p75 antibodies (NGFR) represent a negative control. D, Site-directed mutations (Mut) of NRF-1 binding sites on promoters of Grin1, Grin2b, and COX6a1 (one of the 10 nuclear-encoded COX subunits) resulted in significant reductions in luciferase activity compared with the wild type ( $w t)$. $(n=6 \mathrm{for}$ each construct). ${ }^{*} p<0.05,{ }^{* *} p<0.001$. lysates and NRF-1 antibodies. Anti-nerve growth factor receptor p75 antibodies (NGFR) served as a negative immunoprecipitation control. PCRs using primers shown in Table 2 were done to determine which promoters interacted with NRF-1 in vivo. Individual 0.5 and $0.1 \%$ dilutions of input chromatin were used as standards to indicate the efficiency of the PCRs (Fig. 1C). Grin1, Grin $2 b$, and TFB2M each produced a band from DNA coimmunoprecipitated with anti-NRF-1 antibodies at a position identical 
A
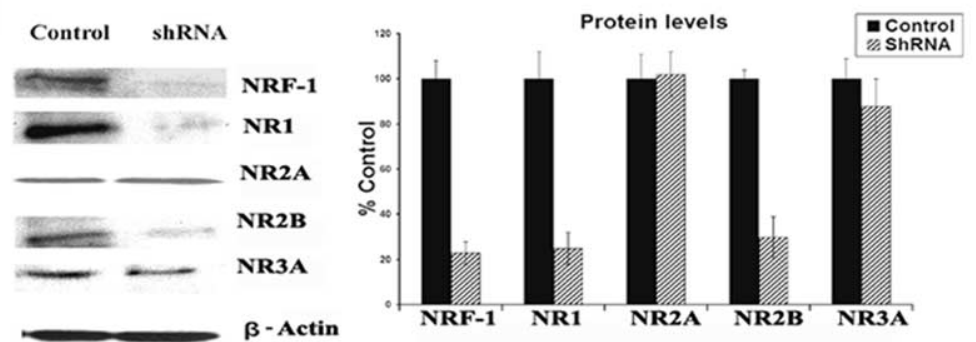

B

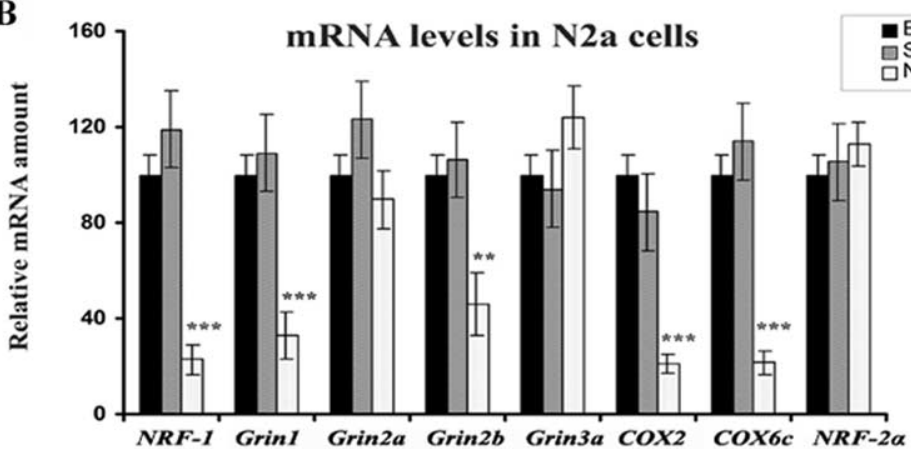

C

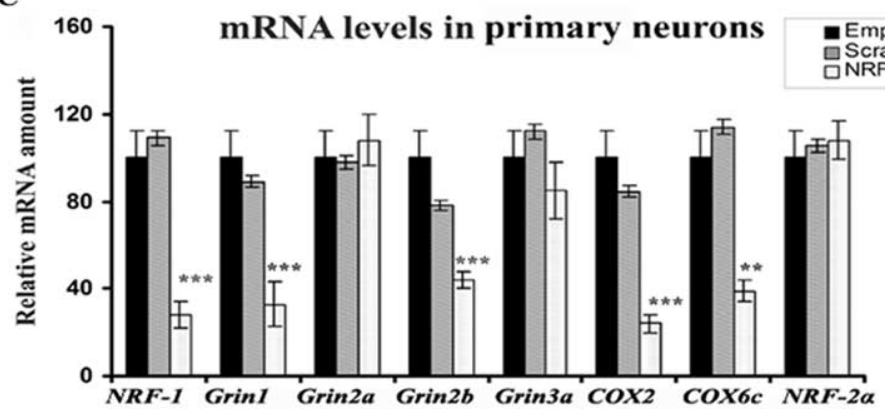

Figure 2. RNA interference-mediated silencing of NRF-1 suppresses mRNAs in NMDAR subunit genes and COX genes. $\boldsymbol{A}$, Western blot reveals a downregulation of NRF-1, NR1, and NR2B protein levels in shRNA-transfected neurons, whereas NR2A and NR3A protein levels were not affected. $\beta$-Actin served as a loading control. $B, C, N 2$ a cells and primary neurons were transfected with shRNA against NRF-1 (light bars) or with empty vectors (black bars) or with scrambled shRNA (gray bars). NRF- $2 \alpha$ served as a negative control. NRF-1, Grin1, Grin2b, COX2 (mitochondrial-encoded), and COX6c (nuclear-encoded) subunit mRNAs show significant decreases in shRNA-treated samples compared with those with empty vectors, whereas Grin2a, Grin3a, and NRF-2 $\alpha$ mRNAs remained unchanged. $n=6$ for each data point. ${ }^{* *} p<0.01,{ }^{* * *} p<0.001$.

to that from the genomic DNA control (input) (Fig. $1 C$ ). However, Grin $2 a$, Grin $3 a$, and $\beta$-actin yielded no bands (Fig. $1 C$ ). In all cases, coimmunoprecipitation with NGFR antibodies did not yield any PCR product.

\section{Mutational analysis of NRF-1 binding}

Based on EMSA probes (Table 1) that formed NRF-1 specific complexes (Fig. 1 $A, B$ ), site-directed mutations of these same putative NRF-1 binding sites on Grin 1, Grin $2 b$ and murine COX6a1 promoters were constructed (Table 3), generated in luciferase reporter plasmids, and analyzed by gene transfection. As shown in Figure $1 D$, mutation of NRF- 1 binding sites led to $\sim 35-60 \%$ reduction in promoter activity of Grin1, Grin $2 b$, and COX6a1 genes $(p<$ 0.05-0.001). COX6a1 subunit promoter served as a positive control and confirmed our previous report (Dhar et al., 2008).

\section{NRF-1 silencing by RNA interference}

To determine the effect of silencing NRF-1 transcript on the expression of NMDA receptors, plasmid vectors expressing small hairpin RNA (shRNA) against four target sequences of NRF-1
mRNA were used. These vectors were previously found to silence NRF-1 expression in N2a cells (Dhar et al., 2008). Transfection of neurons with shRNA vectors resulted in $\sim 70-80 \%$ decrease in levels of NRF-1, NR1, and NR2B proteins as measured by Western blots $(p<0.05-0.01)$ (Fig. 2A). However, NR2A and NR3A showed no alterations in protein levels (Fig. 2A). cDNAs from N2a cells (Fig. $2 B$ ) and primary cortical neurons (Fig. 2C) transfected with NRF-1 shRNA vectors, scrambled shRNA vectors, or empty vectors were analyzed with quantitative realtime PCRs. As shown in Figure 2, $B$ and $C$, mRNA levels of NRF-1, Grin1, Grin2b, COX2 (mitochondrial-encoded) and COX6c (nuclear-encoded) were significantly reduced in both $\mathrm{N} 2$ a cells and primary neurons transfected with shRNA compared with those transfected with empty vectors. The extent of reduction ranged between 65 and 80\% $(p<0.05-$ 0.01 ). However, the expressions of Grin $2 a$, Grin3a, and nuclear respiratory factor $2 \alpha$ (NRF-2 $\alpha$, a negative control) remained unchanged. The scrambled shRNA also did not have any effect on any mRNA level tested (Fig. $2 B, C$ ).

\section{Response of NMDA receptor and COX subunit mRNAs to $\mathrm{KCl}$ depolarizing stimulation}

To determine if the expressions of Grin 1 and Grin $2 b$ genes in N2a cells responded directly to depolarizing stimulation, cells were subjected to $20 \mathrm{~mm}$ of potassium chloride for $5 \mathrm{~h}$, a regimen previously found to activate NRF-1 and COX gene expressions in primary neurons (Zhang and Wong-Riley, 2000a; Liang and WongRiley, 2006; Liang et al., 2006; Yang et al., 2006). As shown in Figure $3 A$ for primary neurons, depolarizing stimulation resulted in a significant increase in the expressions of NRF-1, Grin1, Grin $2 b, C O X 2$, and COX $6 c$ genes, as monitored by real-time quantitative PCR $(p<$ $0.05-0.001)$. The increase ranged from 50 to $90 \%$.

Effect of NRF-1 silencing on COX, Grin1, and Grin2b mRNAs in the presence of $\mathrm{KCl}$ stimulation

To investigate the response of NMDAR and COX subunit genes to $\mathrm{KCl}$ after NRF-1 silencing, N2a cells transfected with shRNA against NRF-1 were subjected to $20 \mathrm{~mm}$ of $\mathrm{KCl}$ for $5 \mathrm{~h}$. As shown in Figure $3 B$, depolarizing stimulation without gene silencing resulted in a significant increase in the expressions of Grin1, Grin2a, Grin2b, Grin3a, COX2 and COX $6 c$ genes, as monitored by real-time quantitative PCR $(p<0.05)$. The increase ranged from 140 to $170 \%$, indicating that $\mathrm{KCl}$ has a general stimulatory effect on transcription (at least of the genes tested). However, in the presence of NRF-1 silencing, mRNA levels of Grin1 and Grin $2 b, \mathrm{COX} 2$ and $\mathrm{COX} 6 c$ were not upregulated by $\mathrm{KCl}$. However, NRF-1 silencing did not prevent Grin $2 a$ and Grin $3 a$ from being upregulated by $\mathrm{KCl}$, and their levels remained higher than those of 
controls $(p<0.05)$ but not different from those with $\mathrm{KCl}$ alone. These results confirmed the specificity of NRF-1 in the regulation of Grin1, Grin2b, and COX subunits in response to increased neuronal activity.

Effect of mutating NRF-1 binding sites on the response of Grin 1 and Grin2b promoters to $\mathrm{KCl}$ stimulation

To further verify that NRF-1 binding is necessary for the upregulation of Grin 1 and Grin $2 b$ transcripts in the presence of $\mathrm{KCl}$, these binding sites were mutated in Grin1 and Grin $2 b$ promoters (Table 3). As shown in Figure $3 C$ for N2a cells, mutation of NRF-1 sites severely downregulated the expression of Grin1 and Grin $2 b$ genes, as monitored by luciferase assays, and prevented their upregulation by $\mathrm{KCl}$.

NRF-1 overexpression increased Grin1, Grin2b, and COX subunit mRNA levels and rescued neurons from tetrodotoxininduced transcript reduction

A low concentration of TTX $(0.4 \mu \mathrm{M})$ has been shown to decrease levels of $C O X$ subunit mRNAs as well as COX enzyme activity in vivo and in primary neurons (WongRiley et al., 1998a,b; Liang et al., 2006). To determine if overexpression of NRF-1 could rescue not only COX but also Grin transcripts, a $p S G 5 N R F-1$ construct (a gift from Dr. Scarpulla) for NRF-1 overexpression was transfected into primary neurons that were then exposed to TTX $(0.4$ $\mu \mathrm{M})$ for $3 \mathrm{~d}$. When neurons were transfected with empty vectors, exposure to TTX led to a $60-80 \%$ reduction in mRNA levels of NRF-1, Grin1, Grin2a, Grin2b, Grin3a, COX2, and COX6c (Fig. 4A-G), indicating an overall suppressive effect of TTX on gene expressions in neurons. Neurons transfected with the pSG5NRF-1 construct over-expressing NRF-1 had a $700 \%$ increase in NRF-1 mRNAs $(p<0.001)$ (Fig. $4 A)$ and a $70-$ $85 \%$ increase in message levels of Grin 1 , Grin2b, COX2, and COX6c (Fig. 4B-E) compared with empty vector controls $(p<0.05-0.01)$. However, there was no change in Grin2a and Grin3a mRNA levels with NRF-1 overexpression (Fig. $4 F, G)$. When exposed to TTX, neurons transfected with NRF-1 expressed $60 \%$ more NRF- 1 mRNA and 30-60\% more Grin1, Grin2b, COX2, and COX6c transcripts compared with those with empty vectors $(p<0.05-0.001)$, but the levels of Grin $2 a$ and Grin3a remained low and not different from those transfected with empty vectors and exposed to TTX. These results confirmed that NRF-1 could rescue Grin1, Grin2b, and COX, but not Grin2a and Grin3a mRNA levels, from being downregulated by TTX.

C

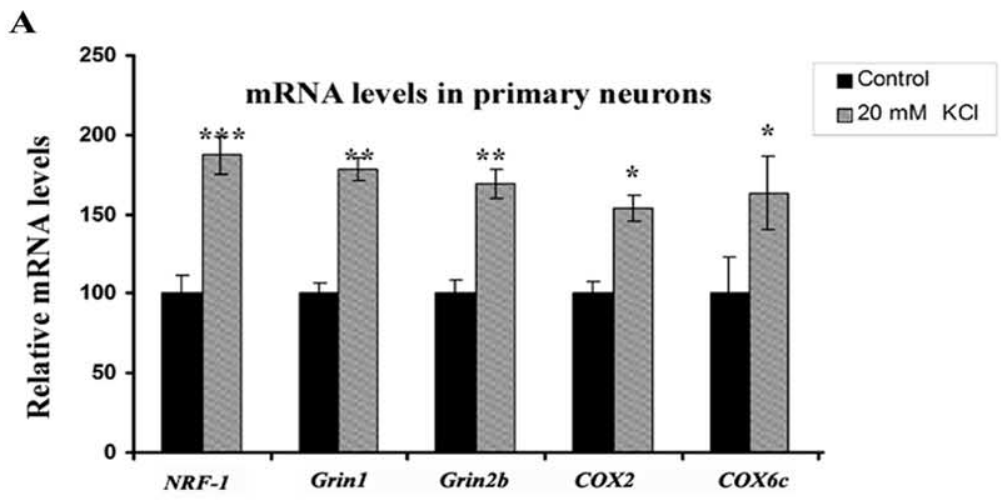

B mRNA levels in N2a cells
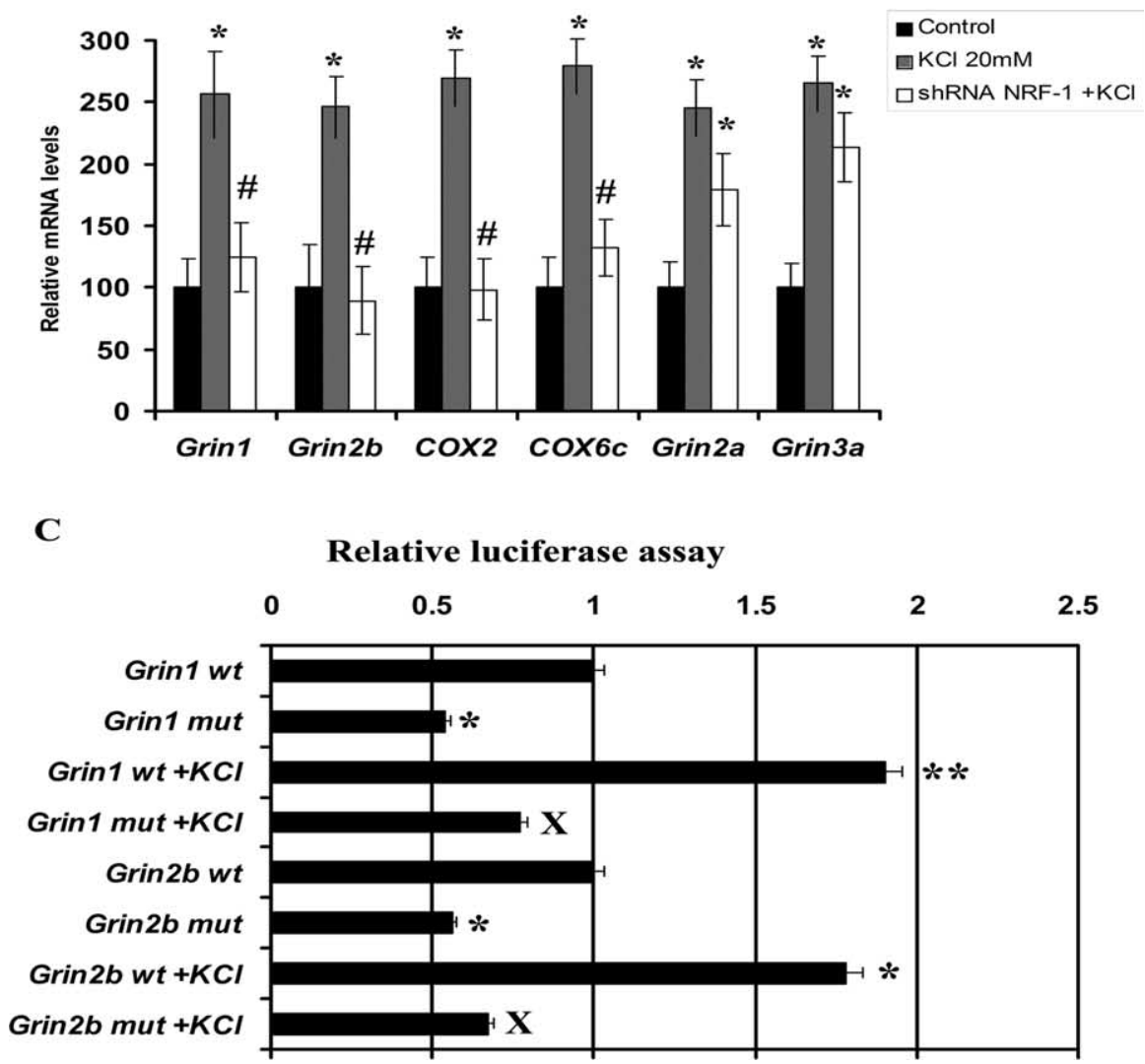

Figure 3. Depolarization-induced upregulation of mRNA levels and promoter gene expressions of NMDAR and COX subunits in neurons and the effects of NRF-1 silencing or binding site mutation. $A$, KCI depolarization induced an upregulation of NRF-1, Grin 1, Grin2b, COX2, and COX6c in primary neurons analyzed with real-time quantitative PCR. ${ }^{*} p<0.05,{ }^{* *} p<0.01,{ }^{* * *} p<0.001$ compared with controls. $\boldsymbol{B}$, Comparable results as in $\boldsymbol{A}$ were obtained in N2a cells. NRF-1 silencing with shRNA prevented the upregulation of these transcripts by $\mathrm{KCl}$. Grin2 $a$ and Grin $3 a$ were also upregulated by $\mathrm{KCl}$, indicating a general stimulatory effect of $\mathrm{KCl}$ on neurons. However, NRF-1 silencing did not prohibit these transcripts from being induced by $\mathrm{KCl}$, as their levels are significantly different from controls, but are not different from those of $K C l$ alone. ${ }^{*} p<0.05$ compared with controls. All ${ }^{*} p$ values $(<0.05)$ were compared with $20 \mathrm{~mm} \mathrm{KCl}$ alone. Values in $\boldsymbol{A}$ and $\boldsymbol{B}$ each represent mean \pm SEM of combined data from three independent experiments. $\boldsymbol{C}$, Site-directed mutations (mut) of NRF-1 binding sites on Grin1 and Grin2b promoters resulted in a significant reduction in luciferase activity compared with their wild-type (wt) controls. $\mathrm{KCl}$ depolarization increased promoter activity in the wild type but not in mutated Grin1 and Grin2b. ( $n=6$ for each construct). ${ }^{*} p<0.05,{ }^{* *} p<0.01$ compared with Grin 1 and Grin2b wild type. $X=p<0.01$ compared with Grin 1 and Grin2b wt with $\mathrm{KCl}$ depolarization.

Conservation of NRF-1 binding sites among mouse, rat, and human Grin1 and Grin2b promoters

The sequences of murine Grin1 and Grin2b subunit genes were aligned with homologous regions in the rat and human genomes to determine if NRF-1 binding sites tested in the present study were conserved in other species. Results showed a high degree of 
A

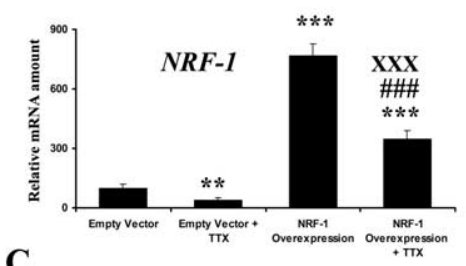

C

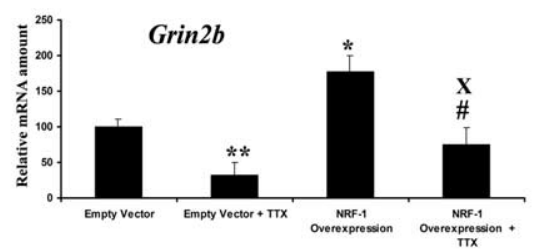

$\mathbf{E}$

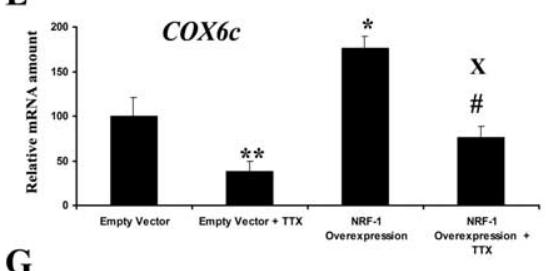

G

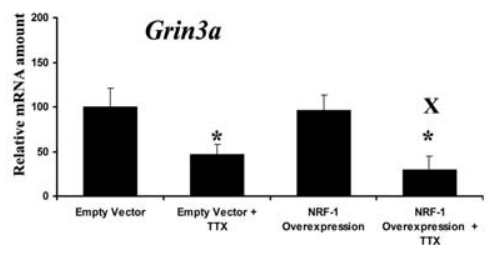

B

D
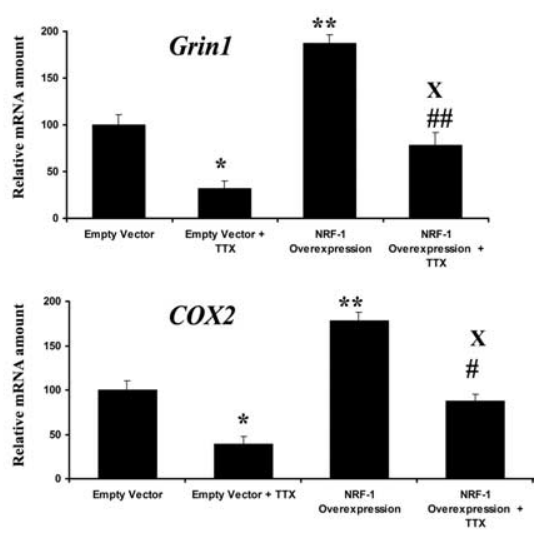

$\mathbf{F}$

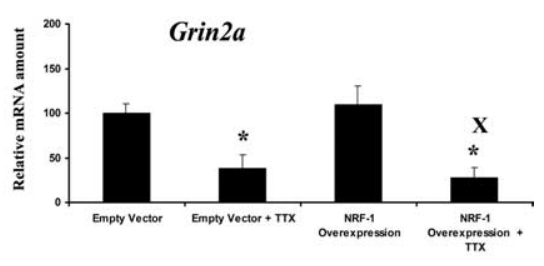

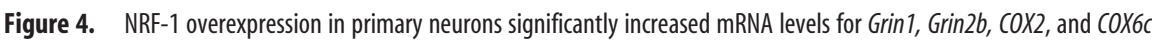
genes and rescued them from TTX-induced suppression. NRF-1, Grin1, Grin2b, COX2, COX6c, Grin2a, and Grin3a mRNA levels (A-G) were all reduced by TTX compared with controls, indicating a generalized depressive effect of TTX on neurons. Overexpression of NRF-1 significantly increased transcript levels of NRF-1, Grin1, Grin2b, COX2, and COX6c, but not of Grin2a and Grin3a. Overexpression of NRF-1 was able to rescue NRF-1, Grin1, Grin2b, COX2, and COX6c but not Grin2a and Grin3a transcripts from being downregulated by TTX. ( $n=6$ for each group). All ${ }^{*} p$ values were compared with empty vectors $\left({ }^{*} p<0.05,{ }^{* *} p<0.01,{ }^{* *} p<\right.$ $0.001)$. All ${ }^{\#} p$ values were compared with empty vector $+\operatorname{TTX}\left({ }^{\#} p<0.05,{ }^{\# \#} p<0.01,{ }^{\# \# \#} p<0.001\right)$, and all ${ }^{x}$ values were compared with NRF-1 overexpression ( $\left.{ }^{\mathrm{x}} p<0.05,{ }^{\mathrm{xxx}} p<0.001\right)$.

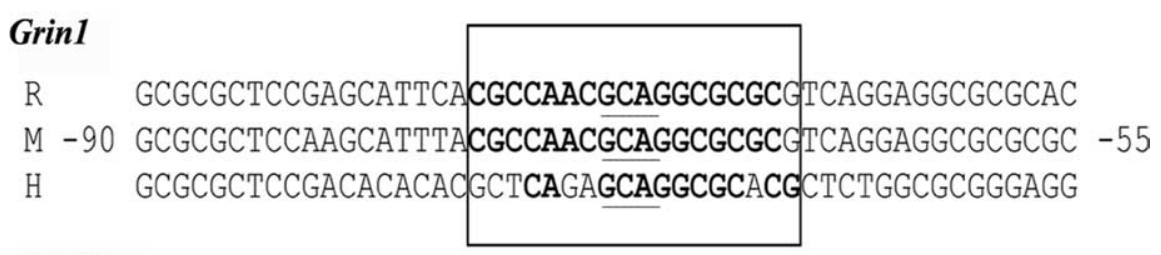

\section{Grin2b}

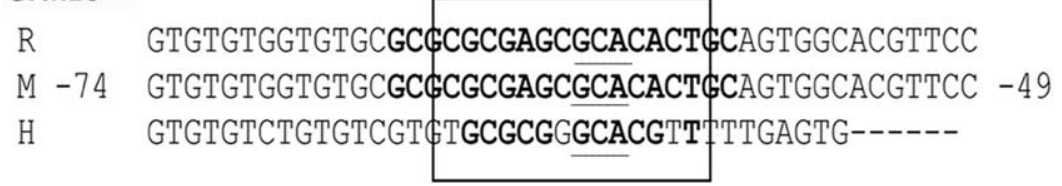

Figure 5. Aligned partial sequences of Grin 1 and Grin $2 b$ promoters from rat (R), mouse (M), and human (H) genomes indicate conservation of atypical NRF-1 binding sites. Conserved binding site sequences are in boldface. Solid boxes highlight NRF-1 sites that are highly conserved in all three or at least two species. The underlined GCA is an invariant sequence for NRF-1 binding for Grin (this study) and for COX (Dhar et al., 2008) promoters.

homology (60-100\%) among the three species (Fig. 5). Thus, NRF-1 sites are highly conserved among mice, rats, and humans.

\section{Discussion}

The present study documents for the first time that NMDA receptor subunits 1 and $2 \mathrm{~b}$ and COX subunit genes are regu- lated by the same transcription factor, NRF-1, thus linking glutamatergic synaptic transmission and energy metabolism at the transcriptional level of regulation (Fig. 6). The high homology for NRF-1 binding sites among mice, rats, and humans for Grin 1 and Grin2b (Fig. 5 ) as well as for $C O X$ subunit promoters (Dhar et al., 2008) underscores the conservation of such coregulation through evolution. NRF-1 itself is activated at both protein and mRNA levels by depolarizing neuronal activity (Yang et al., 2006), and it, in turn, coordinates the transcriptional activation of both NMDA receptor and COX subunit genes, thus ensuring that neuronal activity (or at least one major aspect of it) and energy metabolism remain tightly coupled.

Most native NMDA receptors function as heterotetrameric assemblies composed of two glycine-binding NR1 and two glutamate-binding NR2 subunits (Chen and Wyllie, 2006). NR2A and NR2B subunits are required for the induction of long-term potentiation (LTP) in the nucleus accumbens (Schotanus and Chergui, 2008). NR2C and NR2D are mainly embryonic, although they are reportedly still expressed at low levels in the adult cortex (Monyer et al., 1994; Goebel and Poosch, 1999). Likewise, NR3A and 3B are primarily embryonic, although a switch from NR2A to NR3B has been reported in motoneurons during early postnatal development (Eriksson et al., 2002; Fukaya et al., 2005). In the adult cortex and hippocampus, the majority of NMDA receptors are composed of NR1/ NR2A/NR2B subunits (Chazot and Stephenson, 1997; Luo et al., 1997). In isolation, NR1 (Grin1) gene expresses a functional receptor with a weak response activated by glutamate and glycine, whereas none of the NR2 (Grin2) subunits is functional when expressed alone (Moriyoshi et al., 1991). An increasing number of reports have demonstrated the importance of the NR2B subunit in a variety of synaptic signaling events and protein-protein interactions. The NR2B subunit has been implicated in modulating functions such as learning, memory processing, pain perception, and feeding behaviors, as well as being involved in a number of human disorders (Babb et al., 2005). The NR2B subunit appears to be critical for a number of basic structural and functional attributes associated with the NMDA receptor. The formation of heteromeric NR1NR2B receptors in the rat occurs primarily at birth and increases postnatally compared with the development of either 
homomeric NR1 or NR2B receptors due to disturbances during the critical prenatal period (E14-P0). This suggests that the NR1-NR2B receptor complex may play a significant role in postnatal synaptic transmission and rearrangements, such as for specialized receptors, higher affinities, synapse eliminations, and segregations (Loftis and Janowsky, 2003; Babb et al., 2005). The present finding of a coregulation of NR1 and $N R 2 b$ (Grin1 and Grin2b) by NRF-1 is consistent with a functional NR1-NR2B complex and that this complex is potentially regulated concurrently with mitochondrial energy-generating enzymes. Other transcription factor binding sites have been reported for NMDA receptor subunit promoters, such as for Grin1 in humans, rats and chicks (Zimmer et al., 1995; Krainc et al., 1998; ZarainHerzberg et al., 2005), Grin $2 a$ in rats (Liu et al., 2003), and Grin $2 b-d$ and $3 a$ in rats (Goebel and Poosch, 1999). These include SP1 and MAZ binding sites, which reportedly enhanced Grin 1 promoter activity during neuronal differentiation of the P19 cell line (Okamoto et al., 2002). However, their roles in primary neurons were entirely unknown. The present study documents for the first time the functional role that NRF-1 plays in regulating NMDA receptor subunit genes in primary neurons subjected to depolarizing stimulation and TTX blockade. Silencing of NRF-1 prohibited Grin1 and Grin $2 b$ from being upregulated by $\mathrm{KCl}$, whereas overexpression of NRF-1 rescued these transcripts from being downregulated by TTX. Thus, NRF-1 functionally regulates critical NMDA receptor subunit genes in response to changing neuronal activity.

NRF-1 is known to be a key transcriptional activator of nuclear genes encoding a number of mitochondrial respiratory enzymes, including subunits of the five respiratory chain complexes (Scarpulla, 2002, 2006, 2008). Recently, we found that NRF-1 regulates all 10 nuclear-encoded $C O X$ subunit genes in neurons (Dhar et al., 2008). In addition, NRF-1 is necessary for the activation of mitochondrial transcription factor A ( Tfam), transcription specificity factors (TFB1M and TFB2M), and RNAprocessing proteins required for mtDNA transcription and replication (Virbasius and Scarpulla, 1994; Gleyzer et al., 2005). The polycistronic mitochondrial transcript gives rise to 13 polypeptides, three of which form the catalytic core of cytochrome $c$ oxidase enzyme (Wong-Riley et al., 1998c). Thus, NRF-1 regulates all 13 subunits of COX from the two genomes. It is vital for mitochondrial biogenesis, for normal cell growth, and cellular functioning (Scarpulla, 2006, 2008). Silencing of NRF-1 in the present study downregulates both mitochondrial-encoded (COX2) and nuclear-encoded (COX6c) transcripts and prevented their upregulation by $\mathrm{KCl}$. However, overexpression of NRF-1 rescues both transcripts from being severely decreased by TTX. These findings reaffirm the significant role that NRF-1 plays in regulating COX gene expression in neurons (Dhar et al., 2008).

Previously, we found that the level of COX activity in rat primary neuronal cultures, monkey retina, and monkey visual cortex under normal conditions are positively correlated with the intensity of distribution of excitatory neurotransmitters and their receptors, such as glutamate and NMDA receptor subunit NR1 (Nie and Wong-Riley, 1996; Wong-Riley et al., 1998a,b; Zhang and Wong-Riley, 2000b). This is consistent with the fact that repolarization after excitation-induced depolarization is highly energy-dependent and consumes the bulk of ATP produced in the CNS (Wong-Riley, 1989). Under conditions of altered neuronal activity, such as afferent impulse blockade by TTX or depolarizing treatment by $\mathrm{KCl}$, neuronal COX activity is adjusted to match the new energy demand (Wong-Riley, 1989; Zhang and Wong-Riley, 2000a), and such regulation is mainly at the transcriptional level (Wong-Riley et al., 1998b). Changes in neuronal activity likewise affect the expression of glutamate and NMDA receptors (Wong-Riley et al., 1998a,b; this study). Having concurrent regulation of both COX and NMDA receptors at the transcriptional level by the same transcription factor, as assessed by the present study, substantially escalates the efficiency of this regulatory process.

In conclusion, the present study has come full circle in documenting the tight coupling between neuronal activity and energy metabolism beyond the cellular level (Wong-Riley, 1989) to the molecular level. This tight coupling can be initiated and/or maintained at the transcriptional level by having the same transcription factor participate in the regulation of both processes (Fig. 6). NRF-1 can effectively coordinate the expressions of both NMDA receptor and COX subunit genes, thereby orchestrating a smooth and constant interplay between energy consumption of synaptic transmission and energy generation. No doubt, NRF-1 may not act alone. NRF-2, for example, has also been shown to regulate all 13 COX sub- 
units from the two genomes (Ongwijitwat and Wong-Riley, 2005; Ongwijitwat et al., 2006), and the possibility that it may also regulate NMDA receptor subunit genes has yet to be explored. In addition, a transcriptional coactivator, peroxisome proliferator-activated receptor- $\gamma$ coactivator 1 (PGC-1), is known to stimulate a powerful induction of both NRF-1 and NRF-2 (Gleyzer et al., 2005) as well as bind to and coactivate NRF-1 in stimulating Tfam expression (Wu et al., 1999). PGC-1 has been shown to respond swiftly to external cues in non-neuronal cells (Puigserver et al., 2001) and to changing activity in primary neurons (Liang et al., 2006; Meng et al., 2007). The transcriptional machinery for coregulating neuronal activity and energy metabolism is likely to involve all of these critical factors.

\section{References}

Babb TL, Mikuni N, Najm I, Wylie C, Olive M, Dollar C, MacLennan H (2005) Pre- and postnatal expressions of NMDA receptors 1 and 2B subunit proteins in the normal rat cortex. Epilepsy Res 64:23-30.

Chazot PL, Stephenson FA (1997) Molecular dissection of native mammalian forebrain NMDA receptors containing the NR1 C2 exon: direct demonstration of NMDA receptors comprising NR1, NR2A, and NR2B subunits within the same complex. J Neurochem 69:2138-2144.

Chen PE, Wyllie DJ (2006) Pharmacological insights obtained from structure-function studies of ionotropic glutamate receptors. Br J Pharmacol 147:839-853.

Choi DW (1988) Glutamate neurotoxicity and diseases of the nervous system. Neuron 1:623-634.

Dhar SS, Ongwijitwat S, Wong-Riley MTT (2008) Nuclear respiratory factor 1 regulates all ten nuclear-encoded subunits of cytochrome c oxidase in neurons. J Biol Chem 283:3120-3129.

Dingledine R, Borges K, Bowie D, Traynelis SF (1999) The glutamate receptor ion channels. Pharmacol Rev 51:7-61.

Eriksson M, Nilsson A, Froelich-Fabre S, Akesson E, Dunker J, Seiger A, Folkesson R, Benedikz E, Sundström E (2002) Cloning and expression of the human N-methyl-D-aspartate receptor subunit NR3A. Neurosci Lett 321:177-181.

Evans MJ, Scarpulla RC (1990) NRF-1: a trans-activator of nuclear-encoded respiratory genes in animal cells. Genes Dev 4:1023-1034.

Fukaya M, Hayashi Y, Watanabe M (2005) NR2 to NR3B subunit switchover of NMDA receptors in early postnatal motoneurons. Eur J Neurosci 21:1432-1436.

Gleyzer N, Vercauteren K, Scarpulla RC (2005) Control of mitochondrial transcription specificity factors (TFB1M and TFB2M) by nuclear respiratory factors (NRF-1 and NRF-2) and PGC-1 family coactivators. Mol Cell Biol 25:1354-1366.

Goebel DJ, Poosch MS (1999) NMDA receptor subunit gene expression in the rat brain: a quantitative analysis of endogenous mRNA levels of NR1Com, NR2A, NR2B, NR2C, NR2D and NR3A. Mol Brain Res 69:164-170.

Krainc D, Bai G, Okamoto S, Carles M, Kusiak JW, Brent RN, Lipton SA (1998) Synergistic activation of the $N$-methyl-D-aspartate receptor subunit 1 promoter by myocyte enhancer factor $2 \mathrm{C}$ and Sp1. J Biol Chem 273:26218-26224.

Liang HL, Wong-Riley MT (2006) Activity-dependent regulation of nuclear respiratory factor-1, nuclear respiratory factor-2, and peroxisome proliferator-activated receptor gamma coactivator-1 in neurons. Neuroreport 17:401-405.

Liang HL, Ongwijitwat S, Wong-Riley MT (2006) Bigenomic functional regulation of all 13 cytochrome c oxidase subunit transcripts in rat neurons in vitro and in vivo. Neuroscience 140:177-190.

Liu A, Zhuang Z, Hoffman PW, Bai G (2003) Functional analysis of the rat $\mathrm{N}$-methyl-D-aspartate receptor $2 \mathrm{~A}$ promoter: multiple transcription starts points, positive regulation by $\mathrm{Sp}$ factors, and translational regulation. J Biol Chem 278:26423-26434.

Livak KJ, Schmittgen TD (2001) Analysis of relative gene expression data using real-time quantitative PCR and the 2(-delta delta $\mathrm{C}(\mathrm{T})$ ). Methods 25:402-408.
Loftis JM, Janowsky A (2003) The N-methyl-D-aspartate receptor subunit NR2B: localization, functional properties, regulation, and clinical implications. Pharmacol Ther 97:55-85.

Luo J, Wang Y, Yasuda RP, Dunah AW, Wolfe BB (1997) The majority of $\mathrm{N}$-methyl-D-aspartate receptor complexes in adult rat cerebral cortex contain at least three different subunits (NR1/NR2A/NR2B). Mol Pharmacol 51:79-86.

Meguro H, Mori H, Araki K, Kushiya E, Kutsuwada T, Yamazaki M, Kumanishi T, Arakawa M, Sakimura K, Mishina M (1992) Functional characterization of a heteromeric NMDA receptor channel expressed from cloned cDNAs. Nature 357:70-74.

Meng H, Liang HL, Wong-Riley M (2007) Quantitative immunoelectron microscopic analysis of depolarization-induced expression of PGC-1alpha in cultured rat visual cortical neurons. Brain Res 1175:10-16.

Monyer H, Burnashev N, Laurie DJ, Sakmann B, Seeburg PH (1994) Developmental and regional expression in the rat brain and functional properties of four NMDA receptors. Neuron 12:529-540.

Mori H, Mishina M (1995) Structure and function of the NMDA receptor channel. Neuropharmacology 34:1219-1237.

Moriyoshi K, Masu M, Ishii T, Shigemoto R, Mizuno N, Nakanishi S (1991) Molecular cloning and characterization of the rat NMDA receptor. Nature 354:31-37.

Nie F, Wong-Riley MT (1996) Mitochondrial- and nuclear-encoded subunits of cytochrome oxidase in neurons: differences in compartmental distribution, correlation with enzyme activity, and regulation by neuronal activity. J Comp Neurol 373:139-155.

Okamoto S, Sherman K, Bai G, Lipton SA (2002) Effect of the ubiquitous transcription factors, SP1 and MAZ, on NMDA receptor subunit type 1 (NR1) expression during neuronal differentiation. Brain Res Mol Brain Res 107:89-96.

Ongwijitwat S, Wong-Riley MT (2005) Is nuclear respiratory factor 2 a master transcriptional coordinator for all ten nuclear-encoded cytochrome $\mathrm{c}$ oxidase subunits in neurons? Gene 360:65-77.

Ongwijitwat S, Liang HL, Graboyes EM, Wong-Riley MT (2006) Nuclear respiratory factor 2 senses changing cellular energy demands and its silencing down-regulates cytochrome oxidase and other target gene mRNAs. Gene 374:39-49.

Puigserver P, Rhee J, Lin J, Wu Z, Yoon JC, Zhang CY, Krauss S, Mootha VK, Lowell BB, Spiegelman BM (2001) Cytokine stimulation of energy expenditure through p38 MAP kinase activation of PPARgamma coactivator-1. Mol Cell 8:971-982.

Scarpulla RC (2002) Transcriptional activators and coactivators in the nuclear control of mitochondrial function in mammalian cells. Gene 286:81-89.

Scarpulla RC (2006) Nuclear control of respiratory gene expression in mammalian cells. J Cell Biochem 97:673-683.

Scarpulla RC (2008) Transcriptional paradigms in mammalian mitochondrial biogenesis and function. Physiol Rev 88:611-638.

Schotanus SM, Chergui K (2008) Long-term potentiation in the nucleus accumbens requires both NR2A- and NR2B-containing N-methyl-Daspartate receptors. Eur J Neurosci 27:1957-1964.

Virbasius JV, Scarpulla RC (1994) Activation of the human mitochondrial transcription factor A gene by nuclear respiratory factors: a potential regulatory link between nuclear and mitochondrial gene expression in organelle biogenesis. Proc Natl Acad Sci USA 91:1309-1313.

Wikström M, Krab K, Saraste M (1981) Cytochrome oxidase. A synthesis. New York: Academic.

Wong-Riley MT (1989) Cytochrome oxidase: an endogenous metabolic marker for neuronal activity. Trends Neurosci 12:94-101.

Wong-Riley M, Anderson B, Liebl W, Huang Z (1998a) Neurochemical organization of the macaque striate cortex: correlation of cytochrome oxidase with $\mathrm{Na}+\mathrm{K}+$ ATPase, NADPH-diaphorase, nitric oxide synthase, and N-methyl-D-aspartate receptor subunit 1 . Neuroscience 83:1025-1045.

Wong-Riley MT, Huang Z, Liebl W, Nie F, Xu H, Zhang C (1998b) Neurochemical organization of the macaque retina: effect of TTX on levels and gene expression of cytochrome oxidase and nitric oxide synthase and on 
the immunoreactivity of $\mathrm{Na}+\mathrm{K}+\mathrm{ATPase}$ and NMDA receptor subunit I. Vision Res 38:1455-1477.

Wong-Riley MTT, Nie F, Hevner RF, Liu S (1998c) Brain cytochrome oxidase: functional significance and bigenomic regulation in the CNS. In: Cytochrome oxidase in neuronal metabolism and Alzheimer's disease (Gonzalez-Lima F, ed), pp 1-53. New York: Plenum.

Wu Z, Puigserver P, Andersson U, Zhang C, Adelmant G, Mootha V, Troy A, Cinti S, Lowell B, Scarpulla RC, Spiegelman BM (1999) Mechanisms controlling mitochondrial biogenesis and respiration through the thermogenic coactivator PGC-1. Cell 98:115-124.

Yang SJ, Liang HL, Wong-Riley MT (2006) Activity-dependent transcriptional regulation of nuclear respiratory factor-1 in cultured rat visual cortical neurons. Neuroscience 141:1181-1192.
Zarain-Herzberg A, Lee-Rivera I, Rodríguez G, López-Colomé AM (2005) Cloning and characterization of the chick NMDA receptor subunit-1 gene. Brain Res Mol Brain Res 137:235-251.

Zhang C, Wong-Riley MT (2000a) Depolarizing stimulation upregulates GA-binding protein in neurons: a transcription factor involved in the bigenomic expression of cytochrome oxidase subunits. Eur J Neurosci 12:1013-1023.

Zhang C, Wong-Riley MT (2000b) Synthesis and degradation of cytochrome oxidase subunit mRNAs in neurons: differential bigenomic regulation by neuronal activity. J Neurosci Res 60:338-344.

Zimmer M, Fink TM, Franke Y, Lichter P, Spiess J (1995) Cloning and structure of the gene encoding the human N-methyl-D-aspartate receptor (NMDAR1). Gene 159:219-223. 